\title{
IMPLEMENTASI FRAMEWORK CORDOVA SEBAGAI SOLUSI PENGEMBANGAN APLIKASI CROSS-PLATFORM
}

\author{
Nurwanto ${ }^{1}$ \\ ${ }^{1}$ Universitas Muhammadiyah Ponorogo
}

\section{Article Info:}

Dikirim: 12 Mei 2019

Direvisi: 22 Mei 2019

Diterima: 22 Mei 2019

Tersedia Online: 29 Juni 2019

Penulis Korespondensi: Nurwanto

Universitas Muhammadiyah Ponorogo, Ponorogo, Indonesia Email: nurwanto@umpo.ac.id

\begin{abstract}
Abstrak: Dalam beberapa tahun terakhir, pasar perangkat seluler terutama smartphone, telah mengalami pertumbuhan yang luar biasa. Khususnya, smartphone dengan sistem operasi adalah Android dan iOS. iOS dan Android merupakan dua platform dengan pangsa pasar yang tetap signifikan untuk pengembangan aplikasi mobile. Masing-masing platform ini memiliki infrastruktur pengembangannya sendiri. Tantangan utama yang dihadapi penyedia aplikasi adalah menawarkan solusi untuk semua platform di pasar. Namun, untuk mencapai tujuan ini biasanya membutuhkan biaya pengembangan tinggi. Tujuan pengembangan aplikasi cross-platform adalah mempertahankan basis kode yang sama untuk berbagai platform. Dengan demikian, upaya pengembangan dan biaya berkurang secara signifikan. Saat ini, teknologi crossplatform menjadi sangat penting dan saat ini tersedia banyak framework yang dapat digunakan untuk pengembangan aplikasi cross-platform. Salah satu framework yang paling populer adalah Apache Cordova yang menggunakan teknologi HTML, JavaScript dan CSS. Tujuan utama dari penelitian ini adalah mengimplementasikan framework Cordova sebagai solusi pengembangan aplikasi cross-platform. Hasil penelitian ini yaitu menghasilkan 2 aplikasi dengan platform berbeda yang dibangun dengan basis kode tunggal. Dengan framework Cordova memungkinkan mengembangkan aplikasi cross-platform sehingga dapat mengurangi biaya pengembangan. Setelah dilakukan 2 kali pengujian maka hasil yang dapat disimpulkan yaitu kedua aplikasi berfungsi dengan baik akan tetapi terdapat perbedaan pada tampilannya. Tampilan aplikasi yang sudah di-build menjadi APK dengan menggunakan framework Cordova dan dijalankan pada smartphone Android semua bagian ditampilkan secara vertikal menyesuaikan resolusi layar pengguna sedangkan aplikasi yang dijalankan pada browser desktop semua bagian ditampilkan secara horizontal.
\end{abstract}

Kata kunci: android, cordova; cross-platform; HTML5.

Abstract: In the last few years, the smartphones devices market has experienced tremendous growth, particularly for the smartphones that use Android and iOS as the operating systems. $i O S$ and Android are two platforms with rapidlychanging market share for the development of mobile applications. These platforms have their unique and typical development infrastructure. The main issue that must be faced by the providers is providing answers for all platforms problems on the market. Nevertheless, to reach this goal usually requires expensive development costs. The purpose of developing cross-platform applications is to maintain the same code base for various platforms. Therefore, the developmental steps and expenses are able to be significantly reduced. The cross-platform technology has been very important nowadays and there are currently many frameworks that can be used to develop and improve the crossplatform applications. One of the most popular frameworks is Apache Cordova which uses HTML, JavaScript and CSS technology. The main purpose of this study is to apply and effectively use the Cordova framework as the crossplatform application development solution. This study results in the production of two applications with different platforms, that are built within a single code base. The Cordova framework makes it possible to develop cross-platform applications in order to reduce the development costs. After being tested twice, it can be concluded that the two applications function properly, but there are some differences in display. The applications that have been built into an APK using the Cordova framework and run on an Android smartphones are displayed vertically, adjusting the users' screen resolution; while the applications run on the desktop browsers are all displayed horizontally.

Keywords: android, cordova; cross-platform; HTML5. 


\section{PENDAHULUAN}

Dalam beberapa tahun terakhir, pasar perangkat seluler terutama smartphone, telah mengalami pertumbuhan yang luar biasa. Khususnya, smartphone dengan sistem operasi adalah Android dan iOS [1]. iOS dan Android merupakan dua platform dengan pangsa pasar yang tetap signifikan untuk pengembangan aplikasi mobile [2]. Masing-masing platform ini memiliki infrastruktur pengembangannya sendiri.

Tantangan utama yang dihadapi penyedia aplikasi adalah menawarkan solusi untuk semua platform di pasar [3]. Namun, untuk mencapai tujuan ini biasanya membutuhkan biaya pengembangan tinggi yang seringkali sulit didapat. Tujuan pengembangan aplikasi cross-platform adalah mempertahankan basis kode yang sama untuk berbagai platform. Dengan demikian, upaya pengembangan dan biaya berkurang secara signifikan [4].

Saat ini, teknologi cross-platform menjadi sangat penting dan saat ini tersedia banyak framework yang dapat digunakan untuk pengembangan aplikasi cross-platform [5]. Akan tetapi, dalam mengembangkan sebuah aplikasi, sampai saat ini masih belum ada rekomendasi yang seragam apakah menggunakan teknologi web, pendekatan cross-platform, atau Software Development Kit (SDK) native [6].

Tools pengembangan cross-platform pada aplikasi mobile memungkinkan pengembang untuk menulis kode dasar yang unik dan membuat aplikasi yang sama untuk beberapa platform seluler seperti misalnya Android dan iOS. Berbagai framework telah diusulkan untuk mendukung pengembangan aplikasi mobile cross-platform. [7]. Salah satu framework yang paling populer adalah Apache Cordova yang menggunakan teknologi HTML, JavaScript dan CSS yang dijalankan pada wadah web tertentu, ditambah API untuk mengakses fungsi perangkat seluler itu sendiri [3]. Tujuan utama dari penelitian ini adalah mengimplementasikan framework Cordova sebagai solusi pengembangan aplikasi cross-platform.

\section{METODOLOGI PENELITIAN}

Metodologi penelitian dengan melakukan wawancara dan observasi pada UD. Banyu Urip. Wawancara dilakukan untuk mengetahui kebutuhan sistem yang diinginkan oleh pemilik serta observasi dilakukan untuk mengetahui produk apa saja yang tersedia pada UD. Banyu Urip. Langkah selanjutnya adalah pengembangan sistem berdasarkan data yang diperoleh dari wawancara. Perancangan menggunakan model pengembangan perangkat lunak Waterfall.

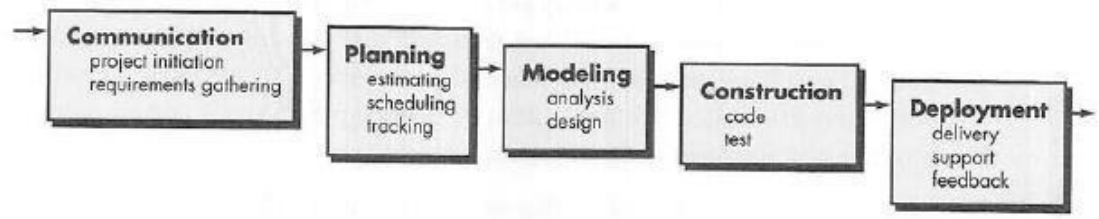

Gambar 1. Waterfall Model [8]

Pada langkah construction ada 2 tahap yang harus diselesaikan yaitu code dan test. Code atau mengembangkan aplikasi dengan bahasa pemrograman yaitu HTML5, Bootstrap CSS dan JavaScript setelah itu dilakukan pengujian (test) dengan dijalankan melalui browser desktop, jika tampilan dan fungsi sudah sesuai dengan kebutuhan maka langkah selanjutnya adalah mengubah aplikasi ke platform Android dengan menggunakan framework Cordova. Karena browser desktop dan struktur resolusi layar smartphone berbeda maka dilakukan pengujian lagi yaitu dengan menjalankan aplikasi pada smartphone Android, jika sudah sesuai maka langkah terakhir adalah mem-build aplikasi menjadi APK. Langka-langkah consruction dapat dilihat pada gambar 2.

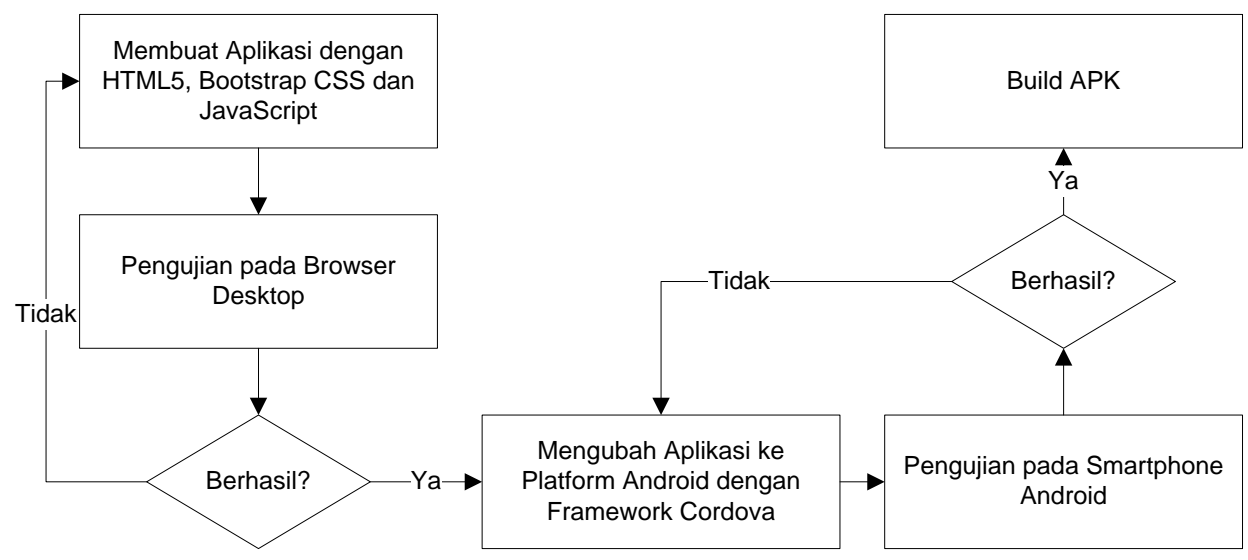

Gambar 2. Langkah Construction 


\section{HASIL DAN PEMBAHASAN}

Perancangan aplikasi dilakukan dengan menerapkan bahasa pemrograman HTML5, Bootstrap CSS dan JavaScript pada framework Cordova. Hasil dari perancangan terdiri dari 2 aplikasi dengan platform yang berbeda.

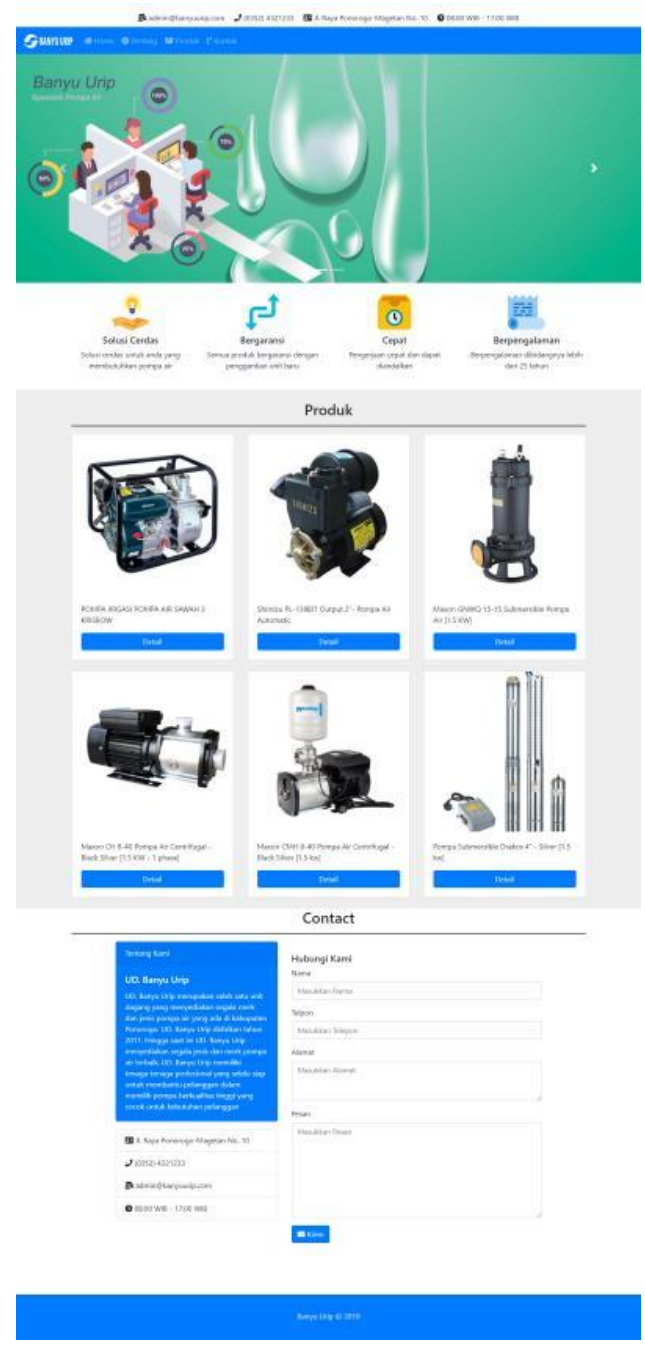

\section{Gambar 3. Tampilan Aplikasi pada Browser Desktop}

Pada gambar 3. Merupakan tampilan aplikasi berbasis web yang dijalankan pada browser desktop. Tampilan aplikasi penulis bagi menjadi 6 bagian yaitu header, navigasi, slider, slogan, produk dan contact. Pada bagian header dan slogan semua konten ditampilkan secara horizontal, pada bagian produk ditampilkan dengan 2 baris dan 3 kolom dan pada bagian contact terdiri dari tentang kami dan hubungi kami yang ditampilkan secara horizontal.

Setelah aplikasi di-build dengan menggunakan framework Cordova menjadi APK, tampilan aplikasi menjadi sedikit berubah karena aplikasi dibangun menggunakan HTML5 dan Bootstrap CSS sehingga tampilan aplikasi menjadi responsive dan menyesuaikan resolusi layar smartphone tanpa mengurangi konten yang ditampilkan sedikitpun. Tampilan pada bagian header menjadi 3 baris yang simetris, bagian navigasi semua menu disembunyikan, untuk mengakses menu yaitu dengan mengklik tombol $\equiv$, untuk bagian slider tidak ada perubahan. Pada bagian slogan, produk dan contact tersusun rapi secara vertikal. Tampilan aplikasi pada smartphone Android disajikan pada gambar 4. 


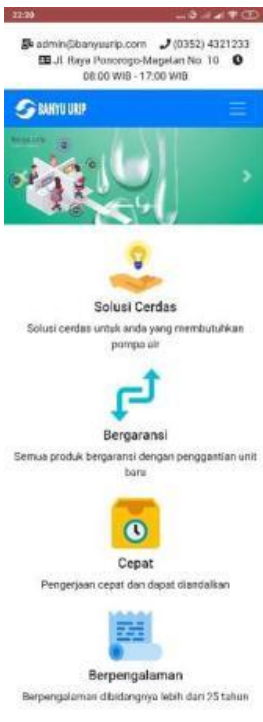

1

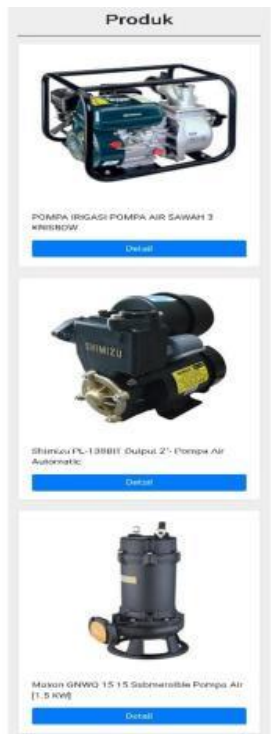

2

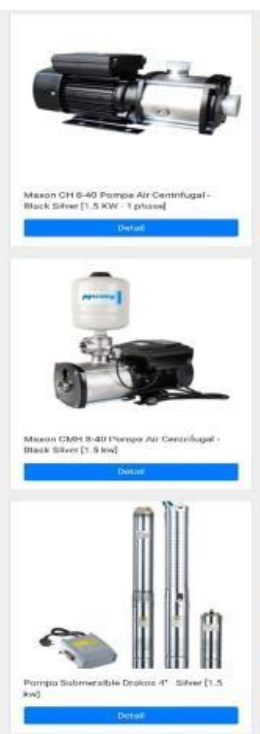

3

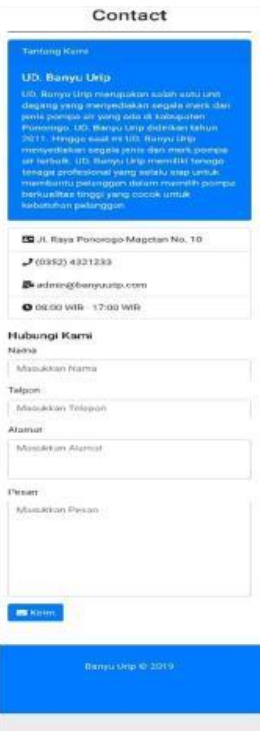

4

Gambar 4. Tampilan Aplikasi APK

\section{KESIMPULAN}

Dengan mengimplementasikan teknologi web seperti HTML5, Bootstrap CSS, JavaScript pada framework Cordova, pengembang dapat membuat aplikasi cross-platform sehingga dapat mengurangi biaya pengembangan. Setelah dilakukan 2 kali pengujian maka hasil yang dapat disimpulkan yaitu kedua aplikasi berfungsi dengan baik akan tetapi terdapat perbedaan pada tampilannya. Tampilan aplikasi yang sudah di-build menjadi APK dengan menggunakan framework Cordova dan dijalankan pada smartphone Android semua bagian ditampilkan secara vertikal menyesuaikan resolusi layar pengguna sedangkan aplikasi yang dijalankan pada browser desktop semua bagian ditampilkan secara horizontal.

\section{DAFTAR PUSTAKA}

[1] F. Rösler, A. Nitze, and A. Schmietendorf, "Towards a Mobile Application Performance Benchmark," Int. Conf. Internet Web Appl. Serv., no. c, pp. 55-59, 2014.

[2] C. Rieger and T. A. Majchrzak, "Towards the definitive evaluation framework for cross-platform app development approaches,” J. Syst. Softw., vol. 153, pp. 175-199, 2019.

[3] L. Corbalan, J. Fernandez, A. Cuitiño, L. Delia, P. Thomas, and P. Pesado, "Development Frameworks for Mobile Devices : A Comparative Study about Energy Consumption,” Dl.Acm.Org, pp. 191-201, 2018.

[4] H. BjörklundBj, "Evaluation of Cross-Platform Mobile Development Tools Development of an Evaluation Framework," 2015.

[5] W. S. El-Kassas, B. A. Abdullah, A. H. Yousef, and A. M. Wahba, "Taxonomy of Cross-Platform Mobile Applications Development Approaches,” Ain Shams Eng. J., vol. 8, no. 2, pp. 163-190, 2017.

[6] C. Rieger and T. A. M. B, "Information Systems: Research, Development, Applications, Education," vol. 300, pp. 18-39, 2017.

[7] C. M. S. Ferreira et al., "An Evaluation of Cross-Platform Frameworks for Multimedia Mobile Applications Development," IEEE Lat. Am. Trans., vol. 16, no. 4, pp. 1206-1212, 2018.

[8] R. S. Pressman, Rekayasa Perangkat Lunak (Pendekatan Praktisi) Edisi 7 : Buku 1. Yogyakarta: Andi, 2012. 